\title{
NOCTURNAL BITING RHYTHMS OF SIX MOSQUITO SPECIES (DIPTERA: CULICIDAE) IN KANDY, SRI LANKA
}

\author{
F.P. AMERASINGHE and N.B. MUNASINGHA \\ Department of Zoology, University of Peradeniya, Peradeniya.
}

(Received : 13 June 1994; accepted: 17 August 1994))

\begin{abstract}
Nocturnal biting rhythms of 6 mosquito species were studied at 3 sites around the city of Kandy in central Sri Lanka from June 1986 to May 1987. Two-man teams working in relays aspirated mosquitoes biting a tethered calf during a $12 \mathrm{~h}$ cycle extending from 1800 to $0600 \mathrm{~h}$ at each site. Catches were segregated at hourly intervals. Only cycles that contained $>20$ females of a particular species, and sites that contained $>5$ such cycles were analyzed for that species. Most of the biting activity in Armigeres subalbatus ( $n=7,549$ ) and Anopheles vagus ( $\mathrm{n}=10,153$ ) occurred during the hour after sunset or before sunrise. Consistent biting activity occurred throughout the night in the other species with a distinct late night peak in An. aconitus $(n=1,376)$, and crepuscular peaks in An. peditaeniatus $(\mathrm{n}=3,252)$, Culex fuscocephala $(\mathrm{n}=17,639)$ and $C x$. tritaeniorhynchus ( $\mathrm{n}=10,504)$. Site-related differences in the biting pattern were seen in $C x$. fuscocephala and $C x$. tritaeniorhynchus but not in the other species. It was concluded that biting activity was governed by a strong endogenous rhythm in the Armigeres and Anopheles species studied, and showed basically similar patterns at different sites. The biting pattern was more variable in the two Culex species, indicating that exogenous factors could substantially modify this activity.
\end{abstract}

Key words: Biting rhythm, Armigeres, Anopheles, Culex, mosquitoes.

\section{INTRODUCTION}

The host feeding activities of mosquitoes have important implications for humans and economically important animals, since it is by this activity that the transmission of disease-causing organisms takes place. Studies on the diel biting rhythms of mosquitoes make an important contribution to determining periods of transmission risk, and are basic to developing methods of personal protection against vector or nuisance mosquitoes.

There are few published studies on the biting patterns of Sri Lankan mosquitoes. Samarawickrema ${ }^{1,2}$ reported on the nocturnal biting activity of Culex quinquefasciatus Say and Mansonia uniformis Theobald, whilst Amerasinghe ${ }^{3}$ and Amerasinghe and Munasingha ${ }^{4}$ described the crepuscular biting activity of several species of the genera Aedes, Culex, Armigeres and

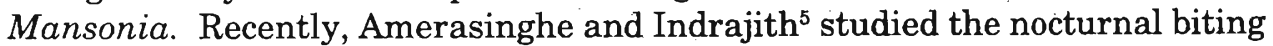
periodicity of 19 species of the genera Aedes, Anopheles, Armigeres, Culex and Mansonia at an irrigated riceland habitat in the low country dry zone of eastern Sri Lanka. In the present paper, we report the results of a study on nocturnal biting activity of mosquito species in a wet zone hill country habitat in the Central Province of the country. The major aim of the study was to compare biting patterns at three closely-situated study sites within the wet zone where macroclimatic factors were similar; another was to compare the activity rhythms 
of mosquito species populations in the wet zone with those in the dry zone reported previously. ${ }^{5}$

\section{METHODS AND MATERIALS}

This study was carried out from June 1986 to May 1987 in and around the city of Kandy (population 100,000, mean elevation $530 \mathrm{~m}$. above mean sea level) in the Central Province of Sri Lanka (Latitude $6^{\circ}-10^{\circ} \mathrm{N}$; Longitude $79^{\circ}-82^{\circ} \mathrm{E}$ ). The terrain in the area was steeply dissected, hilly and rolling. The city centre was urbanized, but outlying areas were semi-rural, with rice fields and generally densely planted home gardens. The area was situated within the wet intermediate hill zone, with annual rainfall ranging from $1800-2500 \mathrm{~mm}$, humidity from $70-80 \% \mathrm{RH}$ and atmospheric temperature from $18-30^{\circ} \mathrm{C}$. Rainfall was heaviest during monsoonal periods (April-June and October-January), but intermonsoonal showers were frequent at other times. Examination of weather data recorded at the nearest meteorological station (at the Central Agricultural Research Station, Gannoruwa) showed that there were no marked seasonal contrasts in temperature or humidity during the year.

Three study sites were selected, Site I (Deiyannawela) situated within the urbanized municipal limits of the city and Sites II and III (Ampitiya and Polgolla, respectively) in the semi-rural areas immediately outside (Fig. 1). At each site, two-man teams working in 3-4h relays aspirated biting females off a calf bait for a $12 \mathrm{~h}$ period commencing at sunset (equated to $1800 \mathrm{~h}$ ) for each date of collection. Catches were segregated at hourly intervals. After transport to the laboratory, the mosquitoes were anaesthetized using chloroform, identified to species level using standard taxonomic keys and descriptions ${ }^{6}$ and counted. The catches for each hour were recorded separately.

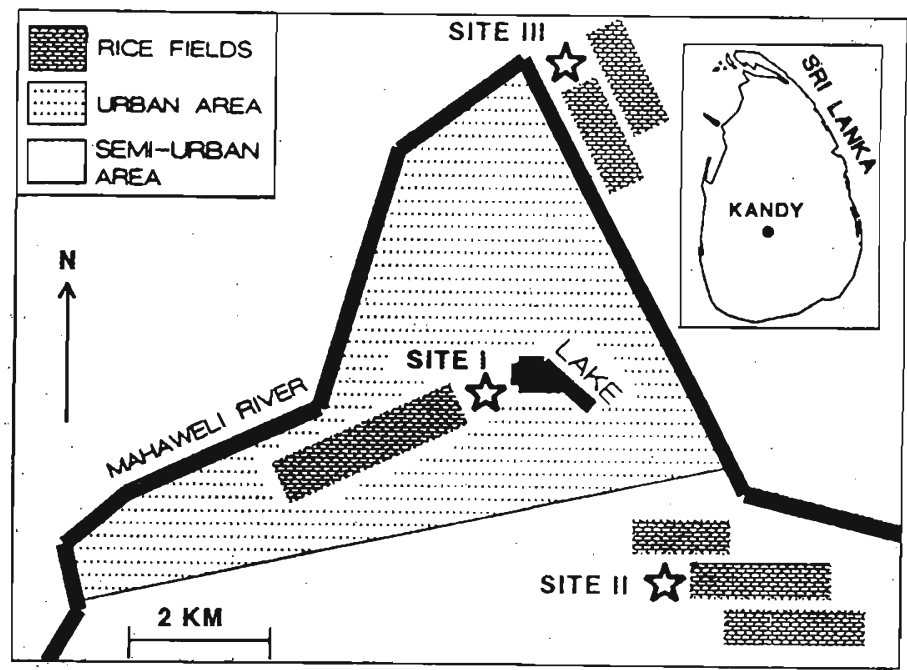

Figure 1: Map of Kandy showing study sites. Inset shows the location of the city of Kandy in Sri Lanka. 
Only nights without rainfall or high winds were considered for analysis, since such factors would tend to disrupt mosquito activity. Nocturnal cycles containing $<20$ females of a particular species were omitted from computations involving that species. Data for sites that yielded $<5$ such valid cycles for a particular species were also omitted. Finally, species in which $<1000$ females were collected in total, were also omitted from analysis. These stringent criteria were used to ensure that biting rhythms were based on substantial numbers of mosquitoes and cycles of activity.

The number of females of a species collected in each hour of a particular cycle were first converted to percentages for that cycle, in order to achieve comparability between cycles relating to different dates, sites and mosquito numbers. The biting rhythms for a given species at different sites are presented as arithmetic means and standard errors of these percentage values for each hour over the $12 \mathrm{~h}$ cycle.

In order to evaluate large-scale differences in biting profiles of a species at different sites, the following data analysis was done. For a particular species, each cycle of collection was characterized by the hour after sunset within which cumulatively $50 \%$ of the females in that cycle were collected. For example, if the $50 \%$ point was reached in hour 4 in a particular cycle of collection and hour 6 in the next cycle, the two cycles were assigned the values of 4 and 6 respectively. For each species, the data series comprising these values at different sites were subjected to analysis of variance (ANOVA) with unequal sample sizes. Data series were normally distributed but displayed heterogeneity of variance (Bartlett's Test, $\mathrm{p}<0.05$ ) in some cases. Thus all data were analyzed by Kruskall-Wallis ANOVA, followed by a non-parametric Tukey-type multiple comparisons test. ${ }^{7}$ The $\alpha$ level of significance was $\mathrm{p} \leq 0.05$.

Histograms depicting nocturnal biting cycles were generated separately for each site in species where ANOVA testing showed significant site-related differences. Data were pooled across sites for those species where site trends were nonsignificant.

\section{RESULTS}

Twenty five species of mosquitoes representing 5 genera (Anopheles, Aedes, Armigeres, Culex and Mansonia) were taken during 114 all-night cycles (38 per site) of collection. Of these, a total of 24 cycles ( 6 at site I, 10 at site II, 8 at site III) were excluded from computations because of adverse weather conditions. When mosquitoes were assessed in relation to valid cycle criteria for species and sites (see Methods and Materials), the analysis of nocturnal biting rhythms was limited to six species (Table 1). 
Table 1: Numbers of nocturnal mosquitoes collected at different study sites in Kandy."

\begin{tabular}{lrrrrr}
\hline Species & \multicolumn{1}{c}{ Site I } & Site II & Site III & Total \\
\hline An. aconitus & $48(2)$ & $385(7)$ & $943(10)$ & $1,376(19)$ \\
An. peditaeniatus & $1,224(15)$ & $751(12)$ & $1,277(19)$ & $3,252(46)$ \\
An. vagus & $6,034(23)$ & $1,782(15)$ & $2,337(17)$ & $10,153(55)$ \\
Ar. subalbatus & $1,365(27)$ & $4,553(25)$ & $1,631(26)$ & $7,549(78)$ \\
Cx. fuscocephala & $10,794(32)$ & $1,795(18)$ & $5,050(25)$ & $17,639(75)$ \\
Cx. tritaeniorhynchus & $5,434(30)$ & $1,318(17)$ & $3,752(24)$ & $10,504(71)$ \\
\hline
\end{tabular}

a Only numbers collected at valid eycles of collection (i.e. $>20$ females per cycle, see Methods and Materials) are included. Figures in parentheses are the numbers of valid cycles. Sites with $<5$ valid cycles were not analyzed for biting rhythms.

Basically similar patterns of biting activity at different sites, as shown by non-significance on statistical testing (Table 2), were seen in An. vagus Doenitz, Ar. subalbatus (Coquillett), An. peditaeniatus Giles, and An. aconitus Doenitz. The first two were clearly crepuscular species, An. vagus with a peak of activity in the hour after sunset declining sharply to minimal levels thereafter (Fig. 2), and Ar. subalbatus with abrupt peaks of activity at sunset and sunrise and little activity in between (Fig. 3). The pattern for An. peditaeniatus (Fig. 4) showed a primary burst of crepuscular activity followed by a lower level of biting throughout the night. Anopheles aconitus (Fig. 5) differed from the above species in that an evening crepuscular peak was not seen: biting activity peaked between 2100 $2400 \mathrm{~h}$. This was followed by a sharp decline in the early hours of the morning and a slight increase towards sunrise.

Table 2: Mean ( \pm S.E.) h after sunset at which $50 \%$ of females per cycle were collected at different study sites.

\begin{tabular}{lcll}
\hline Species & Site I & Site II & Site III \\
\hline An. aconitus & - & $6.0 \pm 0.2$ & $4.5 \pm 0.1$ \\
An. peditaeniatus & $4.9 \pm 0.08$ & $5.1 \pm 0.1$ & $5.2 \pm 0.08$ \\
An. vagus & $1.4 \pm 0.03$ & $2.3 \pm 0.08$ & $1.8 \pm 0.05$ \\
Ar. subalbatus & $2.9 \pm 0.07$ & $3.3 \pm 0.08$ & $4.1 \pm 0.08$ \\
Cx. fuscocephala & $7.2 \pm 0.09^{\mathrm{a}}$ & $5.2 \pm 0.04^{\mathrm{b}}$ & $5.3 \pm 0.06^{\mathrm{b}}$ \\
Cx. tritaeniorhynchus & $6.5 \pm 0.08^{\mathrm{a}}$ & $4.7 \pm 0.05^{\mathrm{b}}$ & $5.0 \pm 0.06^{\mathrm{b}}$ \\
\hline
\end{tabular}

\footnotetext{
- See Table 1 for numbers of valid cycles per species per site. Statistical comparisons of site means by Kruskall-Wallis ANOVA and Tukey's non-parametric multiple comparisons test. Different letters following row means indicate significant differences $(p \leq 0.05)$. Absence of letters indicates nonsignificance of ANOVA.
} 


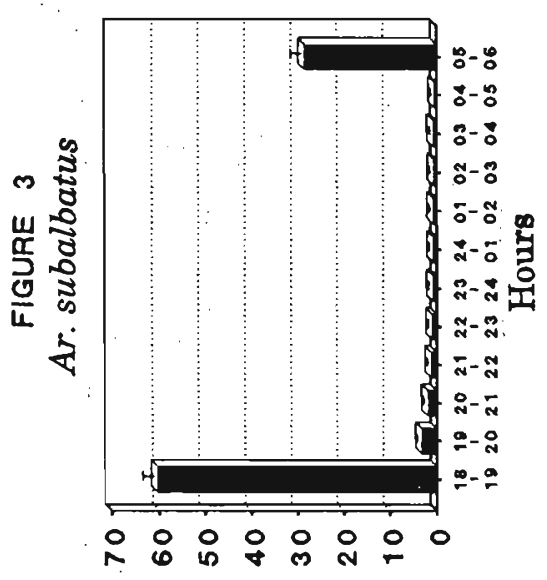

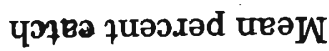

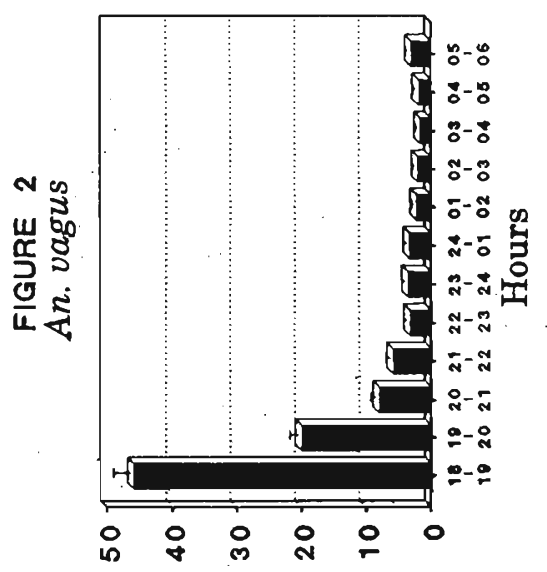

чวฺеว quәวxวd ueวN

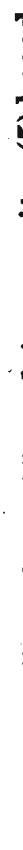

?

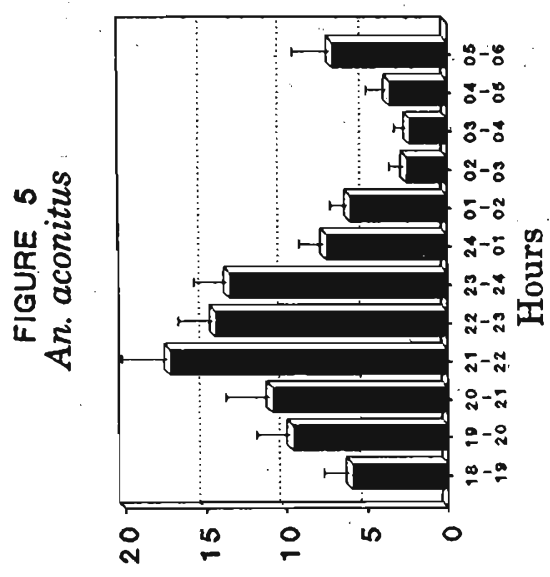

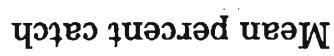

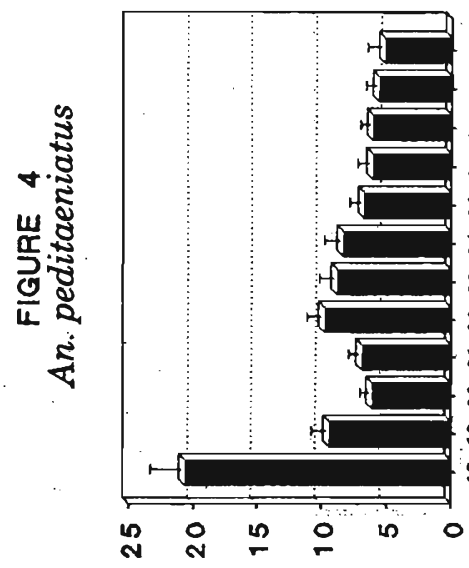

:-๑

:-ะ

$3-8$

2

- -2

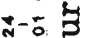

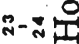

$\pi-2$

$\pi-\frac{1}{2}$

$8-\frac{5}{2}-4$

$0-8$

$-0$

पวาеว ұนววxәd uвวN 
Statistical testing (Table 2) revealed significant site related differences in the activity patterns of two species: $C x$. fuscocephala Theobald (Fig. 6) and $C x$. tritaeniorhynchus Giles (Fig. 7). In both, the differences were related to peak activity occurring in the $2 \mathrm{~h}$ period after sunset at sites II and III, but before sunrise at site I.

\section{DISCUSSION}

Anopheles vagus and Ar. subalbatus were the most strictly crepuscular of the species studied. With the exception of An. aconitus in which biting peaked around $2200 \mathrm{~h}$, the others also showed evidence of crepuscular activity peaks but all were characterized by a consistent pattern of biting extending throughout the night. Haddow et al. ${ }^{8}$ demonstrated that crepuscular activity is related not so much to light intensity per se, but to the rate of change of light at sunset and sunrise. The present study indicated that species such as An. vagus and An. peditaeniatus responded mainly to negative light change (i.e. decreasing light intensity) since their activity peak was associated with sunset. In contrast, Ar. subalbatus, and the Culex species were clearly capable of responding to both negative and positive light change, and showed both dusk and dawn activity peaks.

On average, $A n$. vagus, An. peditaeniatus, An. aconitus, and Ar. subalbatus showed similar biting profiles at different study sites. This rhythmicity may be manifested throughout the distributional range of at least some of these species. For instance, a biting profile identical to that shown in the present study has been reported for $A r$. subalbatus at the western ${ }^{9}$ and eastern ${ }^{10}$ extremes of its range, as well as in India ${ }^{11}$ and the dry zone of Sri Lanka. ${ }^{5}$ The patterns for An. aconitus and An. vagus in Kandy were very similar to those observed in the dry zone of Sri Lanka. ${ }^{5}$ It is clear that a strong endogenous rhythmicity operates in these species. However, the pattern for An. peditaeniatus differed to some extent between the wet and dry zone areas of Sri Lanka, with peak biting occurring at 1800-1900 $\mathrm{h}$ in the wet zone (Kandy) and between 1900-2100 $\mathrm{h}$ in the dry zone. ${ }^{5}$ This difference could be due to the species resting in vegetation some distance away from dry zone village areas, thus arriving later at hosts. A contributory factor could be that the hot, dry, day time conditions of the dry zone delays the onset of activity until the late evening.

Site related variability in $C x$. fuscocephala and $C x$. tritaeniorhynchus resulted primarily from the higher degree of evening crepuscular activity at sites II and III compared to site I, where late-night activity and a morning crepuscular peak were the prominent characteristics. One possibility is that breeding sites and daytime resting sites may have been more distantly located from the urbanized site I compared to sites II and III, resulting in host-seeking mosquitoes arriving later at site I. On the other hand, it is also possible that mosquito activity in the vicinity of this site may have been inhibited by the high level of human activity, and the presence of bright house and street iighting during the evening and early part of the night in the urban area. Interestingly, larger numbers (per valid cycle) of these two species were collected at site I than at the 
Cx. fuscocephala
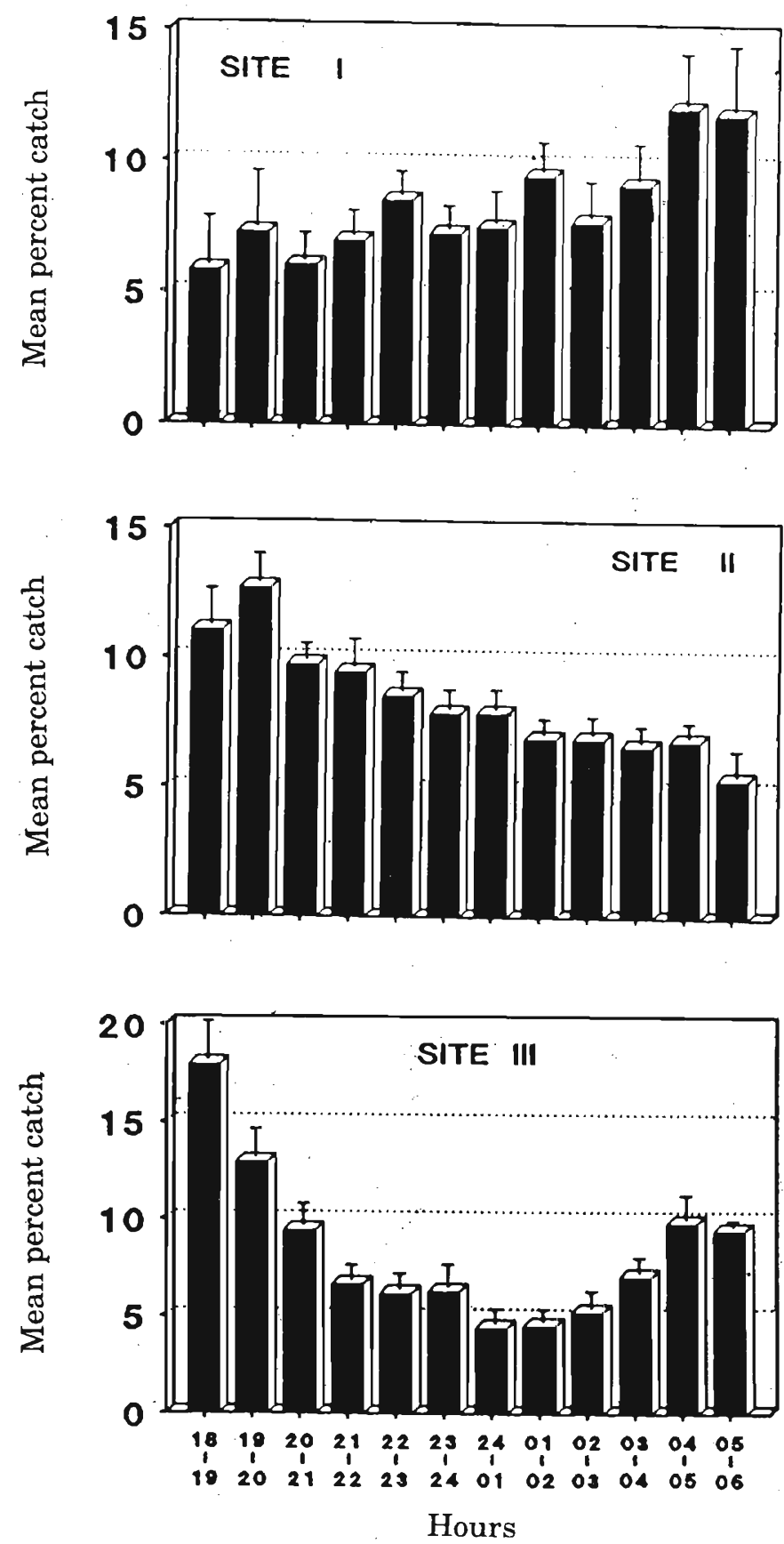

Figure. 6: Nocturnal biting rhythms of $C x$. fuscocephala at different study sites around Kandy. Vertical lines on the bars show standard errors of the mean percentage catch for each hour during the $12 \mathrm{~h}$ cycle. 
Cx. tritaeniorhynchus
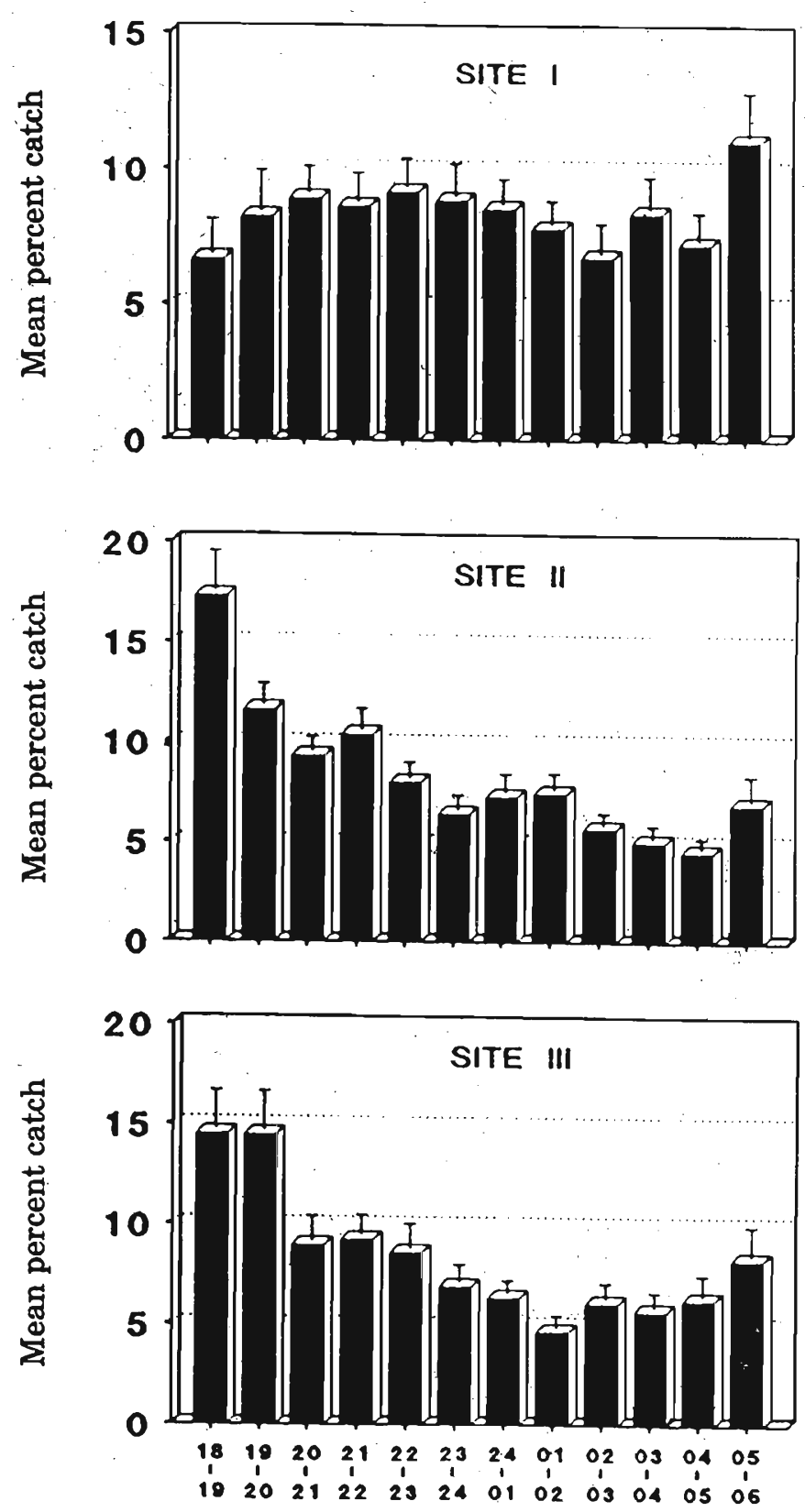

Hours

Figure 7: Nocturnal biting rhythms of $C x$. tritaeniorhynchus at different study sites around Kandy. Vertical lines on the bars show standard errors of the mean percentage catch for each hour during the $12 \mathrm{~h}$ cycle. 
other sites (see Table 1). This could have been a function of greater overall abundance per se at site $\mathrm{I}$, or the result of differences in preferred host availability between the sites. It is well established that $C x$. tritaeniorhynchus and $C x$. fuscocephala are primarily exophilic and zoophilic, and that bovids are a favoured animal host. ${ }^{12}$ Thus, despite the presence of alternative hosts such as humans, dogs, cats, and chickens (goats and pigs were not present in the vicinity of the study sites) substantial numbers of mosquitoes would probably have sought the favoured host in preference to others. One major difference between the urbanized area around site I and the more rural sites II and III lay in the abundance of bovid hosts: the cattle shed at site I was the only one within a $0.25 \mathrm{~km}$ radius of the site, and would have attracted most of the host-seeking mosquitoes in the vicinity. At the more rural sites II and III, many neighbouring households also had 1-4 head of cattle or buffaloes, and the presence of these alternative bovid hosts close-by undoubtedly diverted substantial numbers of mosquitoes away from our specific sites of collection, resulting in lower numbers being recorded.

Biting rhythm variability in $C x$. tritaeniorhynchus and $C x$. fuscocephala. may also have been due to site-related differences in microclimatic factors such as temperature and humidity that could have affected mosquito behaviour. Such aspects were not investigated in the present study. The variability in these two species was further evident when patterns at wet and dry zone areas were compared: in neither species was there a close similarity between patterns at any of the wet zone sites (present study) and the dry zone site reported previously. ${ }^{5}$ Clearly, any endogenous rhythmicity could be substantially modified by exogenous factors in these two species.

Variability in biting profile has been well documented in $C x$. tritaeniorhynchus, one of the most intensively studied oriental mosquitoes because of its importance as a vector of Japanese encephalitis. An unimodal nocturnal biting.profile has been reported in India with the major peak towards midnight, ${ }^{13}$ whilst a biphasic cycle with dusk and dawn peaks has been reported from Pakistan. ${ }^{14}$ A triphasic pattern with dusk, midnight and dawn peaks has been observed in the Philippines. $^{15}$ All 3 types of biting curves have been observed in Japan. ${ }^{16}$ This variability has been attributed to different climatic conditions, especially temperature and humidity, in these varied geographic regions. ${ }^{14}$

Seasonal variations in mosquito nocturnal biting activity have been observed in the more northern areas of the Indo- Pakistan subcontinent where distinct warm and cold seasons occur during an annual cycle. Such changes are probably related to genetic differences in summer and winter populations associated with selection for cold tolerance. ${ }^{14}$ This is not a factor of much consequence in tropical Sri Lanka. In Kandy, for instance, the fluctuation within mean minimum and maximum temperatures over the 12 month period of the study ranged only from $2.5-3.5^{\circ} \mathrm{C}$, and the difference between minimum and maximum for any given month was only $8-12^{\circ} \mathrm{C}$. 
Physiological age and seasonal population changes in age structure are other factors that can potentially impact on mosquito biting activity. In $C x$. tritaeniorhynchus, host-seeking nulliparous females are more active at dusk and parous females at, dawn. ${ }^{16,17}$ Thus, the biting pattern could vary in the short term, depending on the age composition of the population. Since the present study was done over a 12 month period, such short- term fluctuations would have been averaged out. However, the question arises as to whether the site-related differences in biting pattern may have been due to consistent, long-term differences in the age composition of $C x$. tritaeniorhynchus (and also $C x$. fuscocephala) populations at site I compared with sites II and III - an aspect that was not investigated. Clearly, the present results provide the basis for a more detailed investigation of the impact of microecological and physiological factors on the biting activity of these two species.

Culex tritaeniorhynchus is a major vector of epidemic Japanese encephalitis in Sri Lanka, and there is strong evidence for the involvement of $C x$. fuscocephala in transmission as well. ${ }^{18}$ There is also some evidence of the involvement of An.vagus and An. aconitus in malaria transmission. ${ }^{19-21}$ Thus, apart from the ethological considerations discussed above, the elucidation of biting rhythms provides a means of optimizing sampling regimens aimed at obtaining epidemiologically important information on abundance, seasonality and vectorial capacity, and contributes to the knowledge base that is of value in developing defensive strategies against vector or nuisance species.

\section{Acknowledgement}

We are grateful to N.K. Jayawardena, N.G. Indrajith, W. Somapala and T. Alagoda for technical assistance, and G.B. Rathnayake, H.M. Gunarathne Banda and K. Samarakone for field assistance. This work formed part of a larger study on mosquito vector ecology for which funding was provided by the Board on Science and Technology for International Development (BOSTID), U.S. National Academy of Sciences, by way of a grant from USAID.

\section{References}

1. Samarawickrema W.A. (1967). A study of the age-composition of natural populations of Culex pipiens fatigans Wiedemann in relation to the transmission of filariasis due to Wucheraria bancrofti (Cobbold) in Ceylon. Bulletin of the World Health Organization 37: 117-137.

2. Samarawickrema W.A. (1968). Biting cycles and parity of the mosquito Mansonia (Mansonioides) uniformis (Theo.) in Ceylon. Bulletin of Entomological Research 58: 299-314.

3. Amerasinghe F.P. (1988). Crepuscular biting activity of mosquitoes at Peradeniya, Sri Lanka. Tropical Ecology 4: 271-280. 
4. Amerasinghe F.P. \& Munasingha N.B. (1985). Further observations on the mosquito fauna of Udawattakele Forest, Sri Lanka. Ceylon Journal of Science (Biological Science) 17 \& 18: 1-21.

5. Amerasinghe F.P. \& Indrajith N.G. (1994). Nocturnal biting rhythms of mosquitoes (Diptera: Culicidae) in a dry zone habitat in Sri Lanka. Journal of Tropical Zoology (in press).

6. Amerasinghe F.P. \& Ariyasena T.G. (1990): A larval survey of surface waterbreeding mosquitoes during irrigation development in the Mahaweli Project, Sri Lanka. Journal of Medical Entomology 27: 789-802.

7. Zar J.H. (1984). Biostatistical analysis. 2nd Ed. 718 p. Prentice-Hall Inc. N.J.

8. Haddow A.J., Casley D.J.L., O'Sullivan J.P., Ardoin P.M.L., Ssenkubuge Y. \& Kitama A. (1968). Entomological studies from a high steel tower in Zika Forest, Uganda. Part II. The biting activity of mosquitoes above the forest canopy in the hour after sunset. Transactions of the Royal Entomological Society, London 120: 219-236.

9. Aslamkhan M. \& Salman C. (1969). The bionomics of the mosquitoes of the Changa Manga National Forest, West Pakistan. Pakistan Journal of Zoology 1: 183-205.

10. Wada Y. (1969). Ecological studies of Culex tritaeniorhynchus summorosus (Diptera: Culicidae). I. Biting rhythms of the mosquito. Japan Journal of Sanitary Zoology 20: 21-26.

11. Pandian R.S. \& Chandrashekaran M.K. (1980). Rhythms in the biting behaviour of a mosquito Armigeres subalbatus. Oecologia 47: 89-95.

12. Sirivanakarn S. (1976). Medical entomology studies - III. A revision of the subgenus Culex in the Oriental Region (Diptera: Culicidae). Contributions of the American Entomological Institute 12: 1-272.

13. Reuben R. (1971). Studies on the mosquitoes of North Arcot District, Madras State, India. Part 2. Biting cycles and behaviour on human and bovine baits at two villages. Journal of Medical Entomology 8: 127-134.

14. Reisen W.K. \& Aslamkhan M. (1978). Biting rhythms of some Pakistan mosquitoes. Bulletin of Entomological Research 68: 313-330.

15. Reisen W.K. \& Aslamkhan M. (1976). Notes on the biting rhythms of some Philippine mosquitoes on carabao baits. Kalikasan 5: 309-314.

16. Yajima T., Yoshida S. \& Watanabe T. (1971). Ecological studies on the population of adult mosquitoes, Culex tritaeniorhynchus summorosus Dyar. The diurnal activity in relation to physiological age. Japan Journal of Ecology 21: 204-214: 
17. Aslam Y., Reisen W.K. \& Aslamkhan M. (1977). The influence of physiological age on the biting rhythm of Culex tritaeniorhynchus Giles (Diptera: Culicidae). Southeast Asian Journal of Tropical Medicine and Public Health 8: $364-367$.

18. Peiris J.S.M., Amerasinghe F.P., Amerasinghe P.H., Ratnayake C., Karunaratne S.H.P.P. \& Tsai T.F. (1992). Japanese encephalitis in Sri Lanka: The study of an epidemic vector incrimination, porcine infection and human disease. Transactions of the Royal Society of Tropical Medicine and Hygiene 86: 307-313.

19. Amerasinghe F.P., Amerasinghe P.H., Peiris J.S.M. \& Wirtz R.A. (1991). Anopheline ecology and malaria infection during the irrigation development of an area of the Mahaweli Project, Sri Lanka. American Journal of Tropical Medicine and Hygiene 45: 226-235.

20. Mendis C., Gamage-Mendis A.C., de Zoysa A.P.K., Abhayawardena T.A.; Carter R., Herath P.R.J. \& Mendis K.N. (1990). Characteristics of malaria transmission in Kataragama, Sri Lanka: a focus for immuno-epidemiological studies. American Journal of Tropical Medicine and Hygiene 42: 298-308.

21. Ramasamy R., de Alwis R., Wijesundere A. \& Ramasamy M.S. (1992). Malaria transmission at a new irrigation project in Sri Lanka: the emergence of Anopheles annularis as a major vector. American Journal of Tropical Medicine and Hygiene 47: 547-553. 